\title{
Umbilical artery Doppler indices in relation to fetal outcome in high risk pregnancy
}

\author{
Rashmi L. ${ }^{1 *}$, Ashish Bhattacharjee ${ }^{2}$
}

\begin{abstract}
${ }^{1}$ Department of Obstetrics and Gynecology, Subbaiah Medical College and Hospital, Shimoga, Karnataka, India
${ }^{2}$ Department of Obstetrics and Gynecology, Guwahati Medical College and Hospital, Assam, India
\end{abstract}

Received: 04 December 2017

Accepted: 10 January 2018

\author{
*Correspondence: \\ Dr. Rashmi L., \\ E-mail: rashmishimoga916@gmail.com
}

Copyright: () the author(s), publisher and licensee Medip Academy. This is an open-access article distributed under the terms of the Creative Commons Attribution Non-Commercial License, which permits unrestricted non-commercial use, distribution, and reproduction in any medium, provided the original work is properly cited.

\begin{abstract}
Background: Umbilical artery Doppler indices in relation to fetal outcome in high risk pregnancy. The aim of this study was to study the umbilical artery Doppler velocimetry in predicting the fetal outcome in high risk pregnancy. This is a prospective study done over a period of 1 year in Silchar Medical College and Hospital from $1^{\text {st }}$ September 2011 to $31^{\text {st }}$ August 2012. 100 women with singleton pregnancy with high risk admitted in SMCH were subjected to umbilical artery Doppler along with morphology and biometry scan after fulfilling the inclusion and exclusion criteria.

Methods: 100 women with high risk pregnancy were evaluated by umbilical artery velocimetry between 28 and 41 weeks of pregnancy. Outcome of pregnancy was recorded for the normal Doppler group $(\mathrm{n}=79 ; 79 \%)$, the low-end diastolic flow group $(\mathrm{n}=19 ; 19 \%)$ and the group with absent/reversed diastolic flow $(\mathrm{n}=2 ; 2 \%)$.

Results: Mothers with abnormal velocimetry had more number of caesarean sections than those with normal velocimetry. The diagnosis to delivery interval, gestational age at delivery and average birth weight were comparatively lower with higher incidence of admission to neonatal intensive care unit in foetuses with abnormal umbilical Doppler velocimetry. Sensitivity, specificity, positive and negative predictive values of Doppler for detecting abnormal fetal outcome were $43 \%, 83 \%, 33 \%$ and $88 \%$ respectively. Statistical analysis used: sensitivity, specificity and predictive values.

Conclusions: Fetuses with normal flow velocimetry are at lower risk than those with abnormal velocimetry in terms of poor Apgar score and neonatal intensive care admission. The average birth weight of the neonates with abnormal Doppler studies was lower than that of neonates with normal velocimetry. Doppler velocimetry studies of umbilical artery can provide the obstetrician important information regarding fetal wellbeing to help him improve fetal outcome.
\end{abstract}

Keywords: Doppler velocimetry, High risk pregnancy, Umbilical artery

\section{INTRODUCTION}

The development of a good utero-placental circulation is essential for achievement of a normal pregnancy. Intrauterine growth retardation (IUGR) is associated with an increased risk of perinatal mortality, morbidity, and impaired neurodevelopment. The correct detection of the compromised IUGR fetus to allow for timely intervention is a main objective of antenatal care. The most common methods for evaluating health in foetuses identified as SGA are the biophysical profile (BPP) and the non-stress test (NST). Unfortunately, neither of these tests is particularly sensitive for predicting poor outcome in IUGR pregnancies. 
It is here that role of Color Doppler comes to detect these abnormal vascular resistance patterns. The important issue is not the identification of small fetus, but rather the "fetus at risk" for compromise.

Doppler assessment of the placental circulation plays an important role in screening for impaired placentation and its complications of pre-eclampsia, intrauterine growth restriction and perinatal death. Assessment of the fetal circulation is essential in the better understanding of the patho-physiology of a wide range of pathological pregnancies and their clinical management.

Early screening for Preeclampsia may allow vigilant antenatal surveillance and appropriate timing of fetal delivery in order to avoid serious sequelae. Various hemodynamic and biochemical measures have been found to have limited accuracy as screening measures for this condition. ${ }^{1,2}$

Placental insufficiency is the primary cause $(60 \%)$ of intrauterine growth restriction in normally formed fetuses and can be identified using umbilical artery Doppler velocimetry. ${ }^{3}$ Umbilical artery Doppler waveforms provide an estimate of downstream placental vascular resistance and placental blood flow. There is a strong association between reduced end-diastolic umbilical artery blood flow velocity and increased vascular resistance in the umbilical placental microcirculation. As well, abnormal umbilical artery Doppler waveforms have been associated with an increased risk of fetal acidosis.

The association between abnormal umbilical artery Doppler velocimetry and adverse pregnancy outcomes has been investigated widely., ${ }^{4,5}$ Many reports have shown a statistically significant relation between increased fetoplacental resistance, as estimated by either the resistance index or systolic-diastolic ratio (S/D), and the later development of either preeclampsia or fetal growth retardation (FGR) ${ }^{6,7}$ Despite these statistically significant correlations, the clinical utility of umbilical artery Doppler studies has been questioned because of its low predictive values for either preeclampsia or FGR and other adverse outcome in low risk population. ${ }^{8,9}$

In the present study, we determined whether umbilical artery Doppler velocimetry can predict perinatal outcomes in high risk pregnancies between 28 and 42 gestational weeks.

\section{METHODS}

This is a prospective study done over a period of 1 year in Silchar Medical College and Hospital from $1^{\text {st }}$ September 2011 to $31^{\text {st }}$ August 2012. 100 women with singleton pregnancy with high risk admitted in $\mathrm{SMCH}$ were subjected to umbilical artery Doppler along with morphology and biometry scan after fulfilling the inclusion and exclusion criteria. Pregnancies beyond 30 weeks of gestation complicated by severe pre-eclampsia and intrauterine growth restriction or both were selected. Gestational age determination was based on a best estimate from menstrual history, clinical gestational age or fetal biometry preferably in the first trimester or early second trimester. Pregnancies with multiple gestations and congenital anomalies were excluded from the study. Severe pre-eclampsia is defined according to the standard criteria of uncontrolled blood pressure, proteinuria and ultrasound parameters of intrauterine growth restriction. Other pregnancy complications like gestational diabetes mellitus are also included if associated with severe preeclampsia or intrauterine growth restriction was diagnosed based on ultrasound parameters with estimated fetal weight being less than $10^{\text {th }}$ percentile for gestational age (SGA).

Data collected by Philips HD11 XE colour Doppler machine with convex probe $3.5 \mathrm{MHz}$. With Ultrasonography fetal biometry and morphology scan was done, then Doppler mode was switched on. Then transducer is placed over anterior abdominal wall over the uterus and is carefully manipulated till a free loop of umbilical cord seen by Grey scale imaging and colour was used to identify the umbilical artery. Thus, Doppler waveform was obtained. Parameters studied are S/D ratio and RI in umbilical artery. The flow velocity waveforms were considered abnormal if S/D ratio, RI exceeds $95^{\text {th }}$ centile and if there is absent and reverse end diastolic flow.

For the purpose of analysis, the study population was distributed in three groups: a normal Doppler group, a diminished end-diastolic flow group and, an absent diastole or reversed diastolic flow group. These patients were followed up till delivery and details of pregnancy events, labour and delivery and neonatal outcome were noted. The abnormal pregnancy outcomes considered IUGR $\left(<10^{\text {th }}\right.$ percentile birth rate for that gestational age $)$. Perinatal outcomes considered are IUD, stillborn, gestational age at birth, birth weight, Apgar score at 5 minutes, admission to neonatal intensive care unit, need for positive pressure ventilation and neonatal mortality.

\section{Statistical analysis}

These data collected from the study will be analyzed using sensitivities, specificity and predictive value.

\section{RESULTS}

The present study was carried out on 100 women with singleton pregnancy with high risk pregnancies admitted in the department of obstetrics and gynaecology, Silchar Medical College and Hospital during the period of September 2011 to August 2012.

Among the 100 women studied, 21 pregnancies had abnormal Doppler waveforms in umbilical arteries. Doppler waveform of the umbilical artery was considered abnormal if S/D ratio and Resistance index (RI) exceeds 
Table 1: Maternal obstetrical history of study population. $(n=100)$.

\begin{tabular}{|lll|}
\hline Normal & $\begin{array}{l}\text { A bnormal } \\
\text { doppler } \\
\text { n=79 }(79 \%)\end{array}$ & $\begin{array}{l}\text { doppler } \\
\text { n=21 }(21 \%)\end{array}$ \\
\hline Maternal age (mean) & 26.7 years & 29.5 years \\
\hline Parity & $46(58 \%)$ & $14(66 \%)$ \\
\hline Primigravida & $33(42 \%)$ & $7(33 \%)$ \\
\hline Multigravida & $2(2.5 \%)$ & $2(9.5 \%)$ \\
\hline Past h/o of SGA & $3(3.7 \%)$ & $2(9.5 \%)$ \\
\hline Past h/o of PIH & $3(3.7 \%)$ & $1(4.7 \%)$ \\
\hline Past h/o perinatal death & & \\
\hline
\end{tabular}

$95^{\text {th }}$ percentile or if there is absent or reverse end diastolic flow in the foetuses above the gestational age of 28 weeks. The mean for S/D ratio and RI for normal group $(n=79)$ was 2.96 and 0.69 respectively, and for higher S/D and RI group $(n=19)$ was 3.79 and 0.76 respectively (Table 3). In addition, 2 fetuses had absent end diastolic flow.

Small for gestational age babies with abnormal umbilical artery waveform had shorter diagnosis to delivery interval (9.6 days) than those with normal Doppler (Table 2). These fetuses with abnormal umbilical artery Doppler waveforms are at an increased risk for oligohydramnios (Table 3) and for delivery at a lower gestational age.

Table 2: Neonatal outcome in study population.

\begin{tabular}{|c|c|c|c|}
\hline & \multirow{2}{*}{$\begin{array}{l}\text { Normal doppler } \\
\mathbf{N}=79(79 \%)\end{array}$} & \multicolumn{2}{|l|}{$\begin{array}{l}\text { Abnormal doppler } \\
\mathrm{N}=21(21 \%)\end{array}$} \\
\hline & & $\begin{array}{l}\text { Low end diastolic } \\
\text { flow } N=19,(19 \%)\end{array}$ & $\begin{array}{l}\text { Absent /reverse diastolic } \\
\text { flow } N=2,(2 \%)\end{array}$ \\
\hline Delivery at $<36$ weeks of gestation & $\mathrm{N}=12(15.1 \%)$ & $\mathrm{N}=4(21 \%)$ & $\mathrm{N}=2(100 \%)$ \\
\hline Diagnosis to delivery interval & NA & 9.6 days & $<1$ day \\
\hline Average birth weight & $2867.08 \mathrm{~g}$ & $2294.73 \mathrm{~g}$ & $1500 \mathrm{~g}$ \\
\hline NICU admission & $\mathrm{N}=29(36.7 \%)$ & $\mathrm{N}=17(89.4 \%)$ & - \\
\hline Average stay in NICU & 0.91 days & 4 days & - \\
\hline Apgar $<7$ at $5 \mathrm{~min}$ & $\mathrm{~N}=7(8.8 \%)$ & $\mathrm{N}=5(26.3 \%)$ & $\mathrm{N}=2(100 \%)$ \\
\hline \multicolumn{4}{|l|}{ Sex } \\
\hline Female & 44 & 10 & 2 \\
\hline Male & 35 & 9 & - \\
\hline
\end{tabular}

Table 3: Antenatal characteristics of study population $(n=100)$.

\begin{tabular}{|c|c|c|c|}
\hline & \multirow{2}{*}{$\begin{array}{l}\text { Normal doppler } \\
\mathbf{N}=79,(79 \%)\end{array}$} & \multicolumn{2}{|c|}{ Abnormal doppler $\mathbf{N}=21,(21 \%)$} \\
\hline & & $\begin{array}{l}\text { Low end diastolic flow. } N \\
=19,(19 \%)\end{array}$ & $\begin{array}{l}\text { Absent / reverse diastolic } \\
\text { flow. } \mathrm{N}=2,(2 \%)\end{array}$ \\
\hline Mean s/d ratio & 2.9659 & 3.7957 & -- \\
\hline Mean RI & 0.6925 & 0.7636 & -- \\
\hline PIH/Pre-eclampsia & $52(65.8 \%)$ & $15(78.9 \%)$ & $2(100 \%)$ \\
\hline Diabetes & -- & $1(5.2 \%)$ & -- \\
\hline Severe anaemia & $13(16.4 \%)$ & $2(10.5 \%)$ & $1(50 \%)$ \\
\hline IUGR, oligohydramnios & $11(13.9 \%)$ & $11(57.8 \%)$ & $2(100 \%)$ \\
\hline
\end{tabular}

The total fetuses delivered at less than 36 weeks gestation were $12(15.1 \%)$ in normal Doppler group, $4(21 \%)$ in low-end diastolic velocity group and $2(100 \%)$ in the group with absent/reversed end diastolic velocity (Table 2). Frequently the fetuses in the abnormal Doppler group were delivered by caesarean section than those with normal Doppler velocimetry. These neonates had lower birth weight percentiles with higher perinatal asphyxia in terms of lower Apgar score which was below 7 at birth.

Babies with abnormal umbilical artery Doppler studies were more than twice as likely to be admitted to the neonatal intensive care unit and spent longer time there (Table 2). Overall $36.7 \%(n=29)$ of small for gestational age babies with normal umbilical artery Doppler studies were admitted to neonatal intensive care unit (NICU) in contrast to $89.4 \%(n=17)$ small for gestational age babies with low-end diastolic velocity on umbilical artery Doppler.

\section{Maternal characteristics}

There was no major difference in maternal age and parity between mothers with small for gestational age babies of normal umbilical artery velocimetry and those with abnormal umbilical artery velocimetry studies. There was a trend for more underlying medical problems in mothers with abnormal Doppler studies. The obstetric history 
suggested a higher incidence of small for gestational age babies and pregnancy induced hypertension in previous pregnancies of the mothers of the abnormal Doppler group (Table 1).

They had high incidence of pregnancy induced hypertension, diabetes mellitus and severe anaemia developing during the pregnancy (Table 3). $78.9 \%(\mathrm{n}=$ 15) fetuses with low-end diastolic velocity and $100 \%(\mathrm{n}=$
2) with absent / reversed diastolic flow were associated with maternal gestational hypertension.

However, the mothers of small for gestational age babies with normal umbilical artery Doppler studies also had a high incidence of $65.8 \% \quad(n=52)$ pregnancy induced hypertension. Oligohydramnios was associated with pregnancy induced hypertension which constituted $57.8 \%$ of abnormal Doppler studies (Table 3).

Table 4: umbilical artery doppler in predicting IUGR.

\begin{tabular}{lllllllll} 
Doppler test & $\begin{array}{l}\text { True } \\
\text { positive }\end{array}$ & $\begin{array}{l}\text { False } \\
\text { negative }\end{array}$ & $\begin{array}{l}\text { False } \\
\text { positive }\end{array}$ & $\begin{array}{l}\text { True } \\
\text { negative }\end{array}$ & $\begin{array}{l}\text { Sensitivity } \\
\text { Specificity }\end{array}$ & $\begin{array}{l}\text { Positive } \\
\text { predictive } \\
\text { value }\end{array}$ & $\begin{array}{l}\text { Negative } \\
\text { predictive } \\
\text { value }\end{array}$ \\
$\begin{array}{l}\text { Combined } \\
\text { S/D ratio, RI }\end{array}$ & 7 & 9 & 14 & 70 & $43 \%$ & $83 \%$ & $33 \%$ & $88 \%$ \\
\hline
\end{tabular}

\section{DISCUSSION}

In this study umbilical artery Doppler studies were performed in all high-risk pregnancies, this helped us to predict foetal morbidity and mortality in the abnormal umbilical artery Doppler group.

It has been shown by Rochelson BL, and various workers that perinatal morbidity and mortality were significantly greater in small for gestational age babies with abnormal umbilical artery Doppler studies than in those with normal studies. ${ }^{10-13}$

In the present study group there is significant decrease in S/D and RI of umbilical artery as birth weight increases, the birth weight being higher in the normal Doppler group (2867 gm) and lowest in the absent/ reversed end diastolic flow group (1500 gm).

This is in accordance with Fleischer et al who demonstrated that those fetuses with lower birth weight $\left(<25^{\text {th }}\right.$ percentile) had higher placental vascular resistance than those with higher birth weight $\left(>25^{\text {th }}\right.$ percentile $) .{ }^{6}$ In a study done by Malhotra et al birth weight in abnormal Doppler group was $742 \pm 126$ gm and in normal Doppler group was $1680 \pm 259$ gm. $^{14}$

Berkowitz GS et al and various studies have reported on the association of abnormal umbilical artery velocity waveforms with fetal growth restriction and its prediction Alfirevic et al published a systematic review with the meta-analysis addressing the usefulness of Doppler in the surveillance of high-risk pregnancies. ${ }^{15,16}$ Two groups of high-risk pregnant patients were identified and allocated to either a standard fetal assessment protocol or to standard fetal assessment plus Doppler ultrasound testing. Their results showed a decrease in perinatal mortality in the second group. The use of Doppler reduced the odds for perinatal death by as much as $38 \%$ (95\%; CI 15 -
$55 \%$ ). However, it has also been shown that the use of Doppler in low-risk population confers no benefits over standard fetal surveillance. ${ }^{17}$

In the fetuses demonstrating IUGR, a characteristic adaptive vascular mechanism is the cornerstone for fetal survival, this change in the normal vascular physiology and distribution of blood flow is now very well characterized. The identification of a pattern demonstrating fetal adaptation to impaired uteroplacental blood flow constitutes the fetuses affected by IUGR. ${ }^{19}$ Abnormal umbilical artery (UA) Doppler findings have proven useful in distinguishing the constitutionally small and healthy fetus from the fetus with IUGR.

In the present study out of 100 women, 2 small for gestational age fetuses studied, presented with head and abdominal circumference below their reference range, the pregnancy was complicated by oligohydramnios and PIH. These fetuses had absent diastolic flow in umbilical artery, and 1 of them was diagnosed intrauterine death 10 hrs later. Another fetus was born after 14 hours vaginally but turned to be fresh stillborn.

The results shown in Table 2 reveal that fetuses with abnormal umbilical artery velocimetry have a shorter diagnosis of abnormal Doppler to delivery interval, early delivery, decreased birth weight, increased NICU admissions and duration of stay there and with low Apgar scores than those with normal Doppler. Various workers have noticed in fetuses with abnormal umbilical artery Doppler velocimetry a similar poor perinatal outcome. ${ }^{10,12,19,14,15}$ There are old reports suggesting that Doppler studies of velocity waveforms of the umbilical artery are more useful in identifying fetuses prone for IUGR than sonographic estimation of fetal weight. ${ }^{20,21}$

Similarly, our present results showed that there was a significantly increased incidence of neonatal death and 
duration of admission for NICU care in preterm SGA infants with umbilical artery absent/reversed end diastolic flow. $36.7 \%$ of babies with normal Doppler had NICU admission and stayed for average of 1 day, compared to $89.4 \%$ among babies with abnormal Doppler, average days of stay in NICU were 4.

S/D ratio and RI of umbilical artery was significantly higher in those fetuses that had Apgar $<7$ than those who had Apgar $>7$ (Table 2). This shows a higher umbilical vascular resistance and therefore, a decreased placental perfusion in those who had low Apgar at birth.

The mean S/D ratio of umbilical artery was 2.95 in those babies who remained with the mother after delivery as compared to 3.14 in those who got transferred to NICU in the normal umbilical artery Doppler group. On the other hand, in the low end diastolic flow group, the mean S/D ratio of umbilical artery in those babies who remained with their mothers was 3.33 as compared to 3.57 in those admitted to NICU.

In consonance with present study the recent work of Vergani et al found that in fetal growth restricted cases delivered at or beyond 34 weeks gestation with abnormal umbilical artery velocimetry, it independently predicts the likelihood of admission to the NICU for reasons other than low birth weight alone. ${ }^{22}$ Conversely, the study of 2 found that the effect of abnormal umbilical artery Doppler was not important in terms of admission of the newborn to the nursery, birth weight, and gestational age. ${ }^{19}$ The results of present study show that fetuses with abnormal umbilical artery velocimetry have early delivery (at less than 36 weeks of gestation $(21 \%$ versus $15.1 \%)$, increased NICU admission (89.4\% versus $36.7 \%$ ), low Apgar score (26.3\% versus $8.8 \%$ ) than those with normal Doppler. Various workers have noticed in fetuses with abnormal umbilical artery Doppler velocimetry, a similar poor perinatal outcome. ${ }^{19,23,24}$
Mothers of small for gestational age babies with abnormal Doppler studies were more likely to have history of obstetric complications in the previous pregnancy as observed by McCown et al. ${ }^{19}$ They had high incidence of delivering small for gestational age babies, gestational hypertension, and history of perinatal death in the previous pregnancy.

These mothers of small for gestational age babies with abnormal umbilical artery Doppler velocimetry frequently delivered by caesarean section (42.8\% versus $35.4 \%$ ) for fetal distress with subsequent low Apgar scores and greater need for NICU admission than those with normal Doppler as was also noticed by Seyam et al. and Rochelson et al. ${ }^{23,13}$

Perinatal mortality was highest in the absent/ reversed end diastolic flow group. 1 fresh still birth and 1 intrauterine death occurred in this group. Whereas there was no perinatal death in normal Doppler group.

Various studies also suggest that in the most extreme waveform abnormality, there is REDF or AEDF which is considered a very ominous sign of placental compromise and is associated with high perinatal mortality rates.

Madazli et al also studied the severely growth restricted fetuses with AEDF and found a perinatal mortality of $40 \% .{ }^{25}$ Brodszki et al analyzed the outcome of 44 fetuses with REDF and found a perinatal mortality of $59 \% .^{24}$

In a study on the role of umbilical artery Doppler to predict adverse perinatal outcome in women with preeclampsia Yoon et al. ${ }^{26}$ reported, that when gestational age at birth and pre-eclampsia were controlled for, an abnormal umbilical artery Doppler study was still a significant independent predictor of adverse perinatal outcome.

Table 5: Comparison of study at SMCH with previous studies for IUGR with umbilical artery Doppler.

\begin{tabular}{|lllllll|} 
Study & Year & Outcome measures & Sensitivity & Specificity & $\begin{array}{l}\text { Positive } \\
\text { predictive } \\
\text { value }\end{array}$ & $\begin{array}{c}\text { Negative } \\
\text { predictiv } \\
\text { e value }\end{array}$ \\
\hline Fleischer et al & 1985 & IUGR $<10^{\text {th }}$ percentile & 78 & 85 & -- & -- \\
\hline Beattie and Dorman et al & 1989 & IUGR $<10^{\text {th }}$ percentile & 40 & 84 & -- & -- \\
\hline Kofinas et al. & 1991 & IUGR $<10^{\text {th }}$ percentile & 71 & 93 & 83 & 90 \\
\hline Atkinson Et al & 1994 & IUGR $<10^{\text {th }}$ percentile & 18 & 91 & 13 & 94 \\
\hline Pharuhas Chanprapaph et al & 1995 & IUGR $<10^{\text {th }}$ percentile & 53 & 78 & 74 & 65 \\
\hline Trudinger BJ et al. & 2005 & IUGR $<10^{\text {th }}$ percentile & 34 & 93 & 75 & 70 \\
\hline Present study & 2011 & IUGR $<10^{\text {th }}$ percentile & 43 & 83 & 33 & 88 \\
\hline
\end{tabular}

Present study underlines the existence of a strict correlation between umbilical Doppler velocimetry and an increased incidence of perinatal complications in
IUGR fetuses, in consonance with the study of Soregaroli et al. ${ }^{27}$ Similar results were drawn by Baschat et al when they looked at the umbilical artery resistance to determine 
if it can help improve the accuracy of diagnosing IUGR and help in identifying a small fetus at risk of chronic hypoxemia. $^{28}$

Recent meta-analysis of randomized controlled trials suggests that incorporation of umbilical artery Doppler waveform analysis into management protocols for intrauterine growth restricted fetuses significantly decreased perinatal mortality. ${ }^{29}$

Baschat et al provided clear evidence to support that antenatal surveillance is unnecessary despite Ultrasonography findings consistent with or diagnostic of IUGR if both umbilical artery S/D ratio and the amniotic fluid volume are normal. ${ }^{28}$ However, they noticed that commonly, complications occurred to those fetuses with abnormal Doppler studies, which correlates with our study as in Table 2. It is reasonable to assume that decreased uteroplacental perfusion during uterine contractions is likely to further jeopardize gaseous exchange in fetuses with pre-existing abnormal umbilical artery velocimetry.

Hecher et al have pointed out the role of venous Doppler studies in assessing the degree of hypoxemia and in guiding the correct time for delivery. ${ }^{30}$ The fetuses with absent diastole/reversed diastolic flow on follow up have sequelae of neurological deficit in high proportions.

Out of 21 patients with abnormal umbilical artery Doppler 5 patients developed IUGR with a sensitivity of $43 \%$ for both SD and RI. It is similar to opinion by Dorman B et al. ${ }^{31}$ Sensitivity of absent diastolic flow was $100 \%$ (Table 5).

The present result revealed a low sensitivity of S/D ratio and RI (43\%) for IUGR detection similar to the studies of Berkowitz and Anyaegbunam, but, different from the studies of Fleischer and Divon, which revealed a sensitivity as high as $78-87 \% .^{15,32,6,11}$ The discrepancy of research methodology and the characteristics of the studied population may be the important factors leading to the different result. Furthermore, the intra-observer variation and the different location of the Doppler measurement might contribute to the error variance. In addition, the standard criteria of birth weight less than $10^{\text {th }}$ percentile is controversial because it does not make a distinction among fetuses who are constitutionally small, growth restricted and small, and growth restricted but not small. The constitutionally small fetuses are not at high risk and have no rising of feto-placental vascular impedance.

Thus, the misclassification of a normally nourished, healthy, but constitutionally small, neonate as growth restricted may reduce the sensitivity of the test. However, the relatively high specificity of $83 \%$ and negative predictive value of $88 \%$ in the present study also provide suggestive evidence that the umbilical artery S/D ratio and RI may be appropriate for confirmation rather than early detection of IUGR. Nevertheless, the present study has clearly shown the usefulness of the umbilical artery S/D ratio and RI as a non-invasive back up technique that ensures fetal wellbeing.

The value of Doppler velocimetry assessment has been extensively studied for a high-risk pregnancy. It has been proven to significantly reduce perinatal death and lower unnecessary induction of labour in preterm IUGR fetuses as described in a meta-analysis of these trials. Suspicious small fetuses with abnormal Doppler velocimetry require intensive monitoring and possible intervention. However, the perinatal outcome and proper management of IUGR fetuses with normal Doppler remain obscure. Further study in this aspect would be very encouraging and useful.

\section{CONCLUSION}

From the results of this study, we could conclude that the absent/reversed end diastolic flow, as detected by antenatal umbilical artery Doppler is associated with increased risk for poor perinatal outcome.

Funding: No funding sources

Conflict of interest: None declared

Ethical approval: The study was approved by the Institutional Ethics Committee

\section{REFERENCES}

1. Ekholm E. Hemodynamic measures in prediction of pre-eclampsia. Acta Obstetricia Et Gynecologica Scandinavica. 1997;76:101-3.

2. Grunewald C. Biochemical prediction of preeclampsia. Acta Obstet Gynecol Scand. 1997;76:104-7.

3. Gagnon R, Van den Hof M. Diagnostic imaging committee, executive and council of the society of Obstetricians and Gynaecologists of Canada. The use of fetal Doppler in obstetrics. J Obstet Gynaecol Can. 2003;25:601-14.

4. Brar HS, Platt LD. Reverse end-diastolic flow velocity on umbilical artery velocimetry in high-risk pregnancies: an ominous finding with adverse pregnancy outcome. Am J Obstet Gynecol. 1998;159:559-61.

5. Tyrrell S, Obaid AH, Lilfora RJ. Umbilical artery Doppler velocimetry as a predictor of fetal hypoxia and acidosis at birth. Obstet Gynecol. 1989;74:3327.

6. Fleischer A, Schulman H, Farmakides G, Bracero L, Randolph BG. Umbilical artery velocity waveforms and intrauterine growth ratardation. Am J Obstet Gynaecol. 1985;151:502-5.

7. Trudinger BJ, Giles WB, Cook CM, Bombardieri J Collins LE. Fetal umbilical artery flow velocity wave forms and placental resistance clinical significance. Br J Obstet Gynaecol. 1985;92:23-30. 
8. Newnham JP, Patterson LL, James IR, Diepeveen DA, Reid SE. An evaluation of the efficacy of Doppler flow velocity waveform analysis as a screening test in pregnancy. Am J Obstet Gynecol. 1990;162(2):403-10.

9. Abramowicz JS, Warso SL, Sherer DM, Levy DL, Wood Value of random single Doppler study of the umbilical predicting preinatal outcome. J ultrasound Med. 1991;28:327-30.

10. Bohem FH, Gabbe SG. Putting it all together. Clinical Obstet Gynecol. 2002;45:1063-8.

11. Divon MY, Ferber A. Doppler evaluation of fetus. Cinlical Obstet Gynecol. 2002;45:1015-25.

12. Maulik D. Doppler ultrasound velocimetry for fetal surveillance. Clinical Obste Gynecol. 1995;38:91-11.

13. Rochelson B, Schulman H, Fleischer A. The clinical significance of Doppler umbilical artery velocimetry in the small for gestation fetus. Am J Obstet Gynecol. 1987;156:1223-6.

14. Malhotra N, Chanana C, Kumar S. Comparison of perinatal outcome of growth restricted fetuses with normal and abnormal umbilical artery Doppler waveforms. Indian J Med Sci. 2006;60:311-7.

15. Berkowitz GS, Chitkara U, J Rosenberg. Sonographic estimation of fetal weight and Doppler analysis of umbilical artery velocimetry in the prediction of intrauterine growth retardation: a prospective study. Am J Obstet Gynecol. 1988;158:1149-53.

16. Alfervic Z, Neilson JP. Doppler ultrasonography in high risk pregnancies: systemic review and metaanalysis. Am J Obstet Gynecol. 1995;172:1379-87.

17. Bricker L, Neilson JP. Routine Doppler ultrasound in pregnancy. Cochrane Database Syst Rev. 2000;2.

18. Fliesher AC, Romero R, Manning FA, Jeanty P, James AE. The principles and practice of ultrasonography in Obstetrics and Gynaecology, 5th edn. Prentice Hall; 1996.

19. McCowan LM, Harding JE, Stewart AW. Umbilical artery Doppler studies in small for gestational age babies reflect disease severity. Br J Obstet Gynecol 2000;107:916-25.

20. Trudinger BJ, Giles WB, Cook CM. Flow velocity waveforms in the maternal uteroplacental and fetal umbilical placental circulations. Am J Obstet Gynecol. 1985;152:155-63.

21. Fleischer A, Schulman H, Farmakides G. Umbilical artery velocity waveforms and intrauterine growth retardation. Am J Obstet Gynecol. 1985;151:502-5
22. Vergani P, Anderotti C, Roncaglia N. Doppler predictors of adverse neonatal outcome in the growth restricted fetus at 34 weeks gestation or beyond. Am J Obstet Gynecol. 2003;189:1007-11.

23. Seyam YS, Al-Mahmeid MS, Al-Tamimi HK. Umbilical artery Doppler flow velocimetry in intrauterine growth restriction and its relation to perinatal outcome. Int $\mathbf{J}$ Obstet Gynecol 2002;77:131-7.

24. Brodszki J, Hernandez-Andrade E, Gudmundsson S. Can the degree of retrograde diastolic flow in the abnormal umbilical artery flow velocity waveforms predict pregnancy outcome? Ultrasound Obstet Gynecol. 2002;19:229-34.

25. Madazli R. Prognostic factors for survival of growthrestricted fetuses with absent end-diastolic velocity in the umbilical artery. J Perinatol. 2002;22:286-90.

26. Yoon Bh, Lee CM, Kim SW. An abnormal umbilical artery waveform; a strong and independent predictor of adverse perinatal outcome in patients with pre eclampsia. Am J Obstet Gynaecol. 1994;171:713-21.

27. Soregaroli M, Bonera R, Danti L. Prognostic role of umbilical artery Doppler velocimetry in growthrestricted fetuses. J Matern Fetal Neonatal Med. 2002;11:199-203.

28. Baschat AA, Weiner CP. Umbilical artery Doppler screening for the detection of the small fetus in need of ante-partum surveillance. Am J Obstet Gynecol 2000;182:154-8

29. Neilson JP, Alfirevic Z. Doppler ultrasound for fetal assessment in high risk pregnancies. Cochrane Database Syst Rev. 2000;2:CD000073.

30. Hecher K, Campbell S, Doyle P. Assessment of fetal compromise by Doppler ultrasound investigation of the fetal circulation: Arterial, intracardiac and venous blood flow velocity studies. Circ. 1995;91:129-38.

31. Beattie RB, Dornan JC, Antenatal screening for intrauternine growth retardation with umbilical artery Dopple ultrasnography. Br Med J. 1989;298;631-5.

32. Anyaegbunam A, Brustman L, Langer O. A longitudinal evaluation of the efficacy of umbilical Doppler velocimetry in the diagnosis of intrauterine growth retardation. Int $\mathbf{J}$ Gynaecol Obstet. 1991;34:121-5.

Cite this article as: Rashmi L, Bhattacharjee A. Umbilical artery Doppler indices in relation to fetal outcome in high risk pregnancy. Int J Reprod Contracept Obstet Gynecol 2018;7:628-34. 